\title{
Training Adult Entrepreneurs in an Emerging Economy: The Case of Namibia
}

\author{
Nicolene Barkhuizen \\ Department of Industrial Psychology, North-West University, Mmabatho, South Africa, 2745 \\ + 2718389 2652, nicolene.barkhuizen@nwu.ac.za \\ Margaret Bennett \\ Centre for Enterprise Development, Polytechnic of Namibia, Windhoek, Namibia, 9000 \\ +264 61207 2867, mbennett@polytechnic.edu.ac.za
}

\section{Doi:10.5901/mjss.2014.v5n3p298}

\begin{abstract}
The training of adult entrepreneurs in emerging countries remains a challenge as there is no consensus as to the components that should be included in such training initiatives. This research investigates an adult entrepreneurship training programme in terms of its content, delivery methods and outcomes. Surveys were distributed to a convenience sample of Entrepreneurs ( $N=$ 102) who participated in the training programme. The results showed that the trainees benefitted from the knowledge base of training modules and that the training methods applied were effective in the transfer of relevant business knowledge. The results also showed that the training programme contributed to improved business performance, an increased client base, improved work attitude and overall entrepreneurial skills. This research advances the current knowledge in terms of training entrepreneurs effectively in emerging markets such as Namibia.
\end{abstract}

Keywords: Entrepreneurship, Small and Medium Enterprises, Emerging Economies, Training Programmes, Higher Education

\section{Introduction}

The business world is constantly changing. Triggering this phenomenon is the emerging economic and environmental changes, uncertainty in the corporate world, new technology and new emerging world markets. As a result, organizations need to be more creative to adapt to these changes in order to survive and remain sustainable in the future (Brown, 2011; Cummings \& Worley, 2008). Several authors maintain that knowledge is the key for organizations to sustain competitive advantage (see Chua \& Goh, 2009; Cranfield \& Taylor, 2008; Delfmann \& Koster, 2012; Dohse \& Walter, 2012; Howell \& Annansingh, 2013; Rahimi, Arbadisarjou, Allameh \& Aghababaei, 2011; Unger, Rauch, Frese \& Rosenbusch, 2011).

The same applies to Small and Medium Enterprises (SMEs) particularly in emerging markets such as Namibia. The Namibian government has recognized and acknowledged the importance of the SME sector within the economy (Bank of Namibia, 2010). SME activities for example account for $20 \%$ of employment in Namibia, and contribute $12 \%$ to the country's Growth Domestic Product (GDP). Considering these figures it is clear that the empowerment of entrepreneurs can be one of the most powerful avenues for economic growth in Namibia, and, therefore small businesses should be developed and promoted (Bank of Namibia, 2010).

According to Dohse and Walter (2012) an individual's decision to become an entrepreneur critically depends on the multilevel context that provides him/ her with access to strategically relevant knowledge. Entrepreneurs within the Namibian environment are individuals who, due to knowledge of the surrounding markets and unemployment, embark on initiatives to create their own business to make a living. In rare cases, these initiatives expand to sustainable businesses. Entrepreneurs thus need to invest in the acquisition of task-related knowledge in order to possess the right knowledge in the desired form and content under all circumstances to be successful (Howell \& Annansingh, 2013; Laal, 2010; Rahimi et al., 2011; Unger et al., 2011). As mentioned by Knockaert, Ucbasaran, Wright and Clarysse (2011) an organization's (SMEs) success will depend on how it can enhance its own knowledge base, integrate knowledge and apply knowledge to either successfully develop new products/ services or improve current products and services. The effective transfer of knowledge is thus important for competitive advantage and organizational capability (Delfmann \& Koster, 2012).

In this case Higher Education Institutions are essential to create and ensure a smooth transfer of available 
knowledge to smaller organizations in order to stimulate entrepreneurial opportunities (Cranfield \& Taylor, 2008; Delfmann \& Koster, 2012; Dohse \& Walter, 2012). In a similar vein Badelt, Gibb, and EC (cited by Kailer, 2009) propose that universities should become more entrepreneurial focused and develop teaching strategies to enhance the selfemployment of students, alumni, and academic staff. As mentioned by Chua and Goh (2009) the transfer of knowledge involves a developmental process of competencies that can enable individuals to perform the appropriate actions in a specific context.

Although numerous education programs have been designed to empower individuals to become successful entrepreneurs, many of them remained the same over time and are unable to respond to a changing environment (Van Aardt et al., 2011). As Namibia is no exception, but has different challenges and a unique history, the development of an effective training programs for adult entrepreneurs also becomes more challenging. For example, initiatives by the Government of Namibia to ensure the provision of skills and capacity of entrepreneurs has led to an explosion in the training industry, with many organizations, including fly-by-night enterprises, producing and presenting entrepreneurial training programs. Often, entrepreneurs who, in their dire need to escape poverty and unemployment, attend training and are dismally disappointed as there was no business outcome or behavioral change afterwards.

Against this background this research investigates an adult entrepreneurship programs in terms of its content, delivery methods and outcomes concomitant to the perceived values experienced by entrepreneurs. The training program is offered by the Centre for Enterprise Development (CED) of the Polytechnic of Namibia. The Centre for Enterprise Development was established in 2000 and delivers training programs to address the needs of Entrepreneurs in business management. Through tailor-made training courses, base line research and strategies to alleviate poverty, CED diversifies the markets and develops the Namibian labor force. The SME Development Unit focuses on imparting relevant business management knowledge and skills to entrepreneurs.

To date, no research has been done on the effective transfer of knowledge in a training program for adult Entrepreneurs in the Namibian context nor is there any consensus as to the components that should be included in such initiatives. The task facing the CED is to find creative solutions in the training of adult entrepreneurs. Therefore it is important to understand the contribution (or not) of the current entrepreneurship training program of the CED to the Namibian market, while keeping the Namibian market conditions and entrepreneurs' challenges in mind. The role of generally accepted value systems in day-to-day activates and the perceptions of how these are applied by the business community can add to the enhancement of the training program.

The next section of the paper will highlight the theory and research hypotheses related to entrepreneurship training and the outcomes thereof for entrepreneurs. Thereafter, a discussion of the research approach and method will be provided, followed by the results of the research. Finally the article concludes with a discussion of the research results, as well as recommendations for further research.

\section{Theory and Research Hypotheses}

\subsection{Content and Approaches to Entrepreneurship Teaching and Learning}

The extent to which entrepreneurial skills can be transferred or are even worth teaching is a matter of debate among scholars (Delfmann \& Koster, 2012; Dohse \& Walter, 2012; Fiet, 2000). According to Henry (2005) certain elements of entrepreneurship can be taught, as entrepreneurs are not just born, but can also be made. To teach entrepreneurs, trainers should focus on both the "softer" or "experimental" side for example being creative and thinking innovatively, as well as theoretical aspects, such as business and financial management. Theory or "entrepreneurship science" can therefore be taught using conventional methods such as classroom training to provide the entrepreneur with technical skills (Antonites, 2003; Solomon, 2004).

An added component to classroom training is the core practical and informal support like mentoring, counseling, and informal networking events (Dohse \& Walter, 2012). On the other hand, the "art" of entrepreneurship, which is the hub of creation and innovation, does not appear to be transferable in the same direct way, as it is highly subjective and fundamentally experiential nature (Henry, Hill, \& Leitch, 2005a). In order to make sense of the art of entrepreneurship, there is a need for a greater understanding of how people learn entrepreneurial behavior and how entrepreneurial capabilities are developed (Rae, 2006).

Entrepreneurship is the result of the behavior of entrepreneurs, and refers to the impact they have on the economy (Lalani, 2008). Knowledge alone does not create an entrepreneur but the application of the knowledge empowers an individual to make a significant contribution to the economy (Knockaert et al., 2011; Unger et al., 2011). According to 
Henry (2005) the knowledge transfer methods employed in entrepreneurship education and training programs vary considerably according to lectures, presentations, hand-outs, videos, case study-based learning, group discussions, and role playing. In addition, both traditional and non-traditional approaches to learning are featured (Henry, 2005). Training that mainly focuses on theory is considered inappropriate in the teaching of entrepreneurship. Scholars support the less traditional way of teaching, and the adoption of more practical teaching, like role play, simulation games, and problemsolving (Antonites, 2003; Solomon, 2004).

- Hypothesis 1a: Entrepreneurs are able to apply the knowledge acquired in the contents of the training program to their business environments

- Hypothesis $1 \mathrm{~b}$ : The training methods used by the CED contributes to the effective transfer of knowledge for entrepreneurs

\subsection{Objectives and Outcomes of Entrepreneurship Training Programmes}

An entrepreneurship training program's objectives are to train individuals, either for, about, or in entrepreneurship (Mwasalwiba, 2010). Entrepreneurs' level of involvement with the local community can influence the form, course contents and knowledge requirements of entrepreneurship training (Dohse \& Walter, 2012). Entrepreneurship itself is not usually what is taught; rather, it is small business management skills that are provided (Antonites, 2003; Isaacs, Visser, Friedrich \& Brijlal, 2007; Solomon, 2004). Some scholars postulate that receiving business training significantly increases the probability that entrepreneurs will start a business or expand an existing business (Dohse \& Walter, 2012). Thus, entrepreneurial activity, such as starting or expanding businesses, can be encouraged through training (Klinger \& Schündeln, 2007). Entrepreneurial education thus fosters entrepreneurship, and training enhances the skills of business owners.

Key issues that differentiate a more successful learning program for opportunity identification and business startups from an average program is whether there is attitudinal and behavioral modification by the participant after having attended the program (Pretorius, Nieman \& Van Vuuren., 2005). Several studies found changes and improvements in the trainees' attitudes and behaviors, as well as growth in their businesses as a result of the training program they attended (Antonites, 2003; Botha, Van der Merwe, Bester and Albertyn; 2007; Solomon, 2004).

- Hypothesis 2a: The knowledge acquired through the entrepreneurship training offered by the CED contributes to the general business results of the entrepreneurs who attend the training

- Hypothesis 2b: Entrepreneurs' work attitudes change as a result of the entrepreneurship training

\section{Research Design}

This research was done using a quantitative approach as it was considered the best method to address the objective of this study. More specifically a survey design was used, as this allows for the gathering of quantifiable information that can then be used to determine the impact of trends, attitudes and or opinions of a specific population as evident through a sample of the population (Creswell 2009). The present research falls within the positivistic paradigm. The positivistic paradigm holds that research must be limited to what can be observed and measured objectively and exists independently of the feelings and opinions of individuals (Welman, 2010). This research was also cross-sectional in the sense that the data was collected at one point in time (Field, 2009).

\subsection{Sampling}

The target population for this research was all adult entrepreneurs who had completed or attended the CED entrepreneurship program between the years 2008 to 2011 in Namibia. These individuals were owners, co-owners, shareholders, partners and/or directors, and/or employees of businesses within the borders of Namibia. A total of 102 questionnaires were distributed to a purposive convenience sample of entrepreneurs that enrolled for the beginners level training of which all were returned. This represents a $100 \%$ response rate.

Most of the respondents in this research were female (63.7), aged between 30-39 (49\%) years, speaking indigenous languages (74\%), and in possession of Grade 12 certificate and higher qualifications (60\%). $24 \%$ of the Entrepreneurs who participated are involved in the services industry - which include professions in events management, day care for kids, maintenance of buildings and upholstery. Most of the businesses were young, having existed for less than 3 years (40.2\%), did not keep track of their track of their business activities (37.3\%) or had been keeping track of 
their activities for less than one year (27.5\%). Finally, the biographical information obtained showed that access to resources was limited to personal computers (59\%), e-mail (49\%), fax machines (29\%), printers (46\%), and the Internet (53\%), of which the latter was mostly accessed via a cell phone.

\subsection{Data Collection}

For purposes of this study, a questionnaire was developed to measure the effectiveness of the transfer of knowledge during the entrepreneurship training program. The questionnaire consisted of three sections. The first part focused on obtaining the biographical information of the respondents. Biographical information gathered included Gender, Age, Home Language, Educational Qualifications, Time Period that Business has been in existence, Business Category,

The second part of the questionnaire focused on aspects relating to the training of the entrepreneurs. Entrepreneurs were first asked to indicate whether the contents of the eight training modules the attended (i.e. Personal Development, Bookkeeping and Budgeting, Marketing and Sales, General Business Management, Tendering Processes and Procedures, Communication Skills and Customer Care, Production Management and Leadership and Ethics) contributed to the entrepreneurial skills of the respondents and the extent to which the training methods contributed to the transfer of knowledge. Second respondents were asked to indicate the results of the training as a result of the training. These include increase in customers, improved financial systems, more formal marketing structures in place, increase in turnover, better understanding of buying procedures, expansion of business and increase in profits. A variety of response options were used to assess the above and are indicated in the results section.

The third section focused on the entrepreneur's perceptions of whether there is a change in business results and their attitudes as a result of the training. As with section B a variety of response options were used to assess the above and are indicated in the results section.

The survey used in the present study was piloted prior to administration using subject matter experts in the field of survey testing, academic professionals, and employees from the target population to ensure its face and content validity (Cooper \& Schindler, 2008).

\subsection{Data Analyses}

The data analyses were carried out with the aid of SPSS (SPSS Inc, 2013). Descriptive statistics such as frequencies, means, standard deviations, were used due to the descriptive nature of this study.

\section{Results}

Using the dataset described in the previous section, the research objective can now be addressed. First the adequacy of the knowledge contents of the modules is reported. This is followed by the results of the effectiveness of the training methods used in the transfer of knowledge for the trainees. Finally we focus on the results of the transfer of knowledge (i.e. business-related results, turnover results and customer results).

\subsection{Adequacy of the content of the training modules}

The respondents were asked to indicate whether the contents covered in the different training modules enabled them to apply the skills learned in their businesses. The results are presented in Table 1 below.

Table 1: Adequate Coverage of Training Modules

\begin{tabular}{|l|c|c|c|c|c|c|c|}
\hline & $\mathbf{N}$ & Mean & SD & Large extent & Partially & Not at all & Did Not Attend \\
\hline Personal development & 86 & 2.57 & .50 & 49 & 37 & 0 & 16 \\
\hline Bookkeeping and budgeting & 94 & 2.59 & .50 & 55 & 39 & 0 & 8 \\
\hline Marketing and sales & 94 & 2.57 & .50 & 54 & 40 & 0 & 8 \\
\hline General business management & 86 & 2.45 & .52 & 40 & 45 & 1 & 16 \\
\hline Tendering processes and procedures & 51 & 2.35 & .48 & 18 & 33 & 0 & 51 \\
\hline Communication skills and customer care & 94 & 2.55 & .54 & 54 & 38 & 2 & 8 \\
\hline Production management & 72 & 2.60 & .49 & 43 & 29 & 0 & 30 \\
\hline Leadership and ethics & 89 & 2.51 & .52 & 46 & 42 & 1 & 13 \\
\hline
\end{tabular}


From Table 1 it is evident that, on average, the entrepreneurs benefitted the most from the Bookkeeping module and the Production Management module. The contents of the Personal Development and the Marketing and sales training modules also enabled the entrepreneurs to apply these skills in their respective businesses. The results however showed that the modules of Communication Skills and General Business Management need slight improvement, while the Leadership and Ethics module and Tendering Processes modules require substantial improvement. It is important to note that the Production Management and Tendering Process Modules were only introduced later in the program. These results partially confirm research hypothesis $(\mathrm{H} 1 \mathrm{a})$ that entrepreneurs are able to apply the knowledge acquired in the contents of the training program to their business environments.

\subsection{Effectiveness of training methods used for the transfer of knowledge}

Table 2 indicates the training methods that the entrepreneurs considered most effective in the transfer of knowledge.

Table 2: Results of effectiveness of the training methods used

\begin{tabular}{|l|c|c|c|c|c|c|c|c|}
\hline & Mean & SD & Excellent & Good & Neutral & Poor & Very poor & Not used \\
\hline Lecturing & 4.647 & .500 & 67 & 34 & 1 & 0 & 0 & 0 \\
\hline Case studies & 4.157 & 1.192 & 44 & 49 & 2 & 1 & 0 & 6 \\
\hline Role play & 3.990 & 1.432 & 43 & 45 & 4 & 0 & 0 & 10 \\
\hline Practical exercises & 4.382 & .975 & 57 & 36 & 6 & 0 & 0 & 3 \\
\hline Team activities & 4.451 & .828 & 56 & 42 & 2 & 0 & 0 & 2 \\
\hline Small discussion groups & 4.441 & .839 & 56 & 41 & 3 & 0 & 0 & 2 \\
\hline Videos/DVDs & 3.814 & 1.651 & 46 & 33 & 9 & 0 & 0 & 14 \\
\hline Mentorship & 3.461 & 1.833 & 37 & 33 & 12 & 0 & 0 & 20 \\
\hline
\end{tabular}

From Table 2 it is evident that the entrepreneurs benefitted the most from the training methods of lecturing, practical exercises, team activities, and small discussion groups in the transfer of knowledge. Case studies and DVDs were less popular, while role play and mentorship made the smallest contributions. Additional results showed that there is a strong need for twinning with a successful business person and on-the-job training. Business simulation games and time for self-reflection also received a strong response. This section included an open-ended question, where proposals to enhance the learning experience could be noted. Some of the suggestions included the use of local case studies, that training should be over longer period, more capable mentors, visits by trainers to the workplaces, and on-the-job training, as well as offering of the option of e-learning. It should be noted that trainers did visit the workplaces of the entrepreneurs where possible. These results partially confirms research hypothesis $(\mathrm{H} 1 \mathrm{~b})$ that the training methods used by the CED contributes to the effective transfer of knowledge for entrepreneurs.

\subsection{Results achieved by applying knowledge to the work situation}

The respondents were asked to indicate the general business results achieved with the application of the skills learned as part of the training modules. These results include business-related results, changes in work attitude, increase in turnover, and increase in customer numbers. The results achieved in the entrepreneur's businesses as a result of the training are reported in Table 3 below.

Table 3: Results of Learned Skills Applied in the Business

\begin{tabular}{|l|c|c|c|c|c|c|c|}
\hline & $\boldsymbol{N}$ & Mean & SD & Big & Small & None & Did not Attend \\
\hline Increase in customers & 102 & 2.64 & .48 & 65 & 37 & 0 & 0 \\
\hline Improved financial systems & 101 & 2.51 & .54 & 54 & 45 & 2 & 1 \\
\hline Formal marketing structures & 102 & 2.42 & .64 & 51 & 43 & 8 & 0 \\
\hline Increase in turnover & 102 & 2.32 & .58 & 39 & 57 & 6 & 0 \\
\hline Better understanding of buying procedures & 102 & 2.53 & .54 & 56 & 44 & 2 & 0 \\
\hline Expansion of business & 102 & 2.40 & .58 & 46 & 51 & 5 & 0 \\
\hline
\end{tabular}

From Table 3, it is evident that the training mostly led to an increase in customers, improved financial systems, and better 
buying procedures. Although the means were still high, the smallest effect was on formalizing marketing structures, expansion of the business, and increased turnover. Respondents were also asked to indicate the extent to which the training program improved their turnover and client base. The results are reported in Tables 4 and 5 below.

Table 4: Results relating to Increase in Turnover

\begin{tabular}{|l|c|c|c|c|}
\hline & Frequency & Percent & Valid Percent & Cumulative Percent \\
\hline $\mathbf{0} \%$ & 2 & 2.0 & 2.0 & 2.0 \\
\hline Up to $\mathbf{2 5 \%}$ & 42 & 41.2 & 41.2 & 43.1 \\
\hline More than $\mathbf{2 5 \%}$, but less than $\mathbf{5 0} \%$ & 18 & 17.6 & 17.6 & 60.8 \\
\hline More than $\mathbf{5 0 \%}$, but less than $\mathbf{7 5 \%}$ & 18 & 17.6 & 17.6 & 78.4 \\
\hline More than $\mathbf{7 5 \%}$, but less than $\mathbf{1 0 0 \%}$ & 6 & 5.9 & 5.9 & 84.3 \\
\hline More than $\mathbf{1 0 0 \%}$ & 2 & 2.0 & 2.0 & 86.3 \\
\hline Don't know & 8 & 7.8 & 7.8 & 94.1 \\
\hline Confidential & 6 & 5.9 & 5.9 & 100.0 \\
\hline
\end{tabular}

Table 4 shows that most of the entrepreneurs' business profits increased by up to $25 \%$. Some experienced a growth of between 25 and $75 \%$, while a few reported an increase of $75 \%$ or more. Some participants did not want to, or were unable to share this information with the researcher. Table 5 shows that $40 \%$ of the entrepreneurs' client bases increased by $25 \%$ as a result of the training. Others reported an increase of more than $25 \%$, to as much as $100 \%$. There were participants who did not want to, or were unable to, share this information with the researcher.

Table 5: Results relating to Customer Growth

\begin{tabular}{|l|c|c|c|c|}
\hline & Frequency & Percent & Valid Percent & Cumulative Percent \\
\hline $\mathbf{0} \%$ & 4 & 3.9 & 4.0 & 4.0 \\
\hline Up to $\mathbf{2 5 \%}$ & 40 & 39.2 & 39.6 & 43.6 \\
\hline More than 25\%, but less than $\mathbf{5 0 \%}$ & 13 & 12.7 & 12.9 & 56.4 \\
\hline More than $\mathbf{5 0} \%$, but less than $\mathbf{7 5 \%}$ & 18 & 17.6 & 17.8 & 74.3 \\
\hline More than 75\%, but less than $\mathbf{1 0 0} \%$ & 11 & 10.8 & 10.9 & 85.1 \\
\hline More than 100\% & 9 & 8.8 & 8.9 & 94.1 \\
\hline Don't know & 1 & 1.0 & 1.0 & 95.0 \\
\hline Confidential & 5 & 4.9 & 5.0 & 100.0 \\
\hline
\end{tabular}

The results of the change in work attitude as a result of the training are reported in Table 6.

Table 6: Results relating to Change in Attitude

\begin{tabular}{|l|c|c|c|c|c|c|c|}
\hline & Mean & SD & $\begin{array}{c}\text { Strongly } \\
\text { agree }\end{array}$ & Agree & Neutral & Disagree & $\begin{array}{c}\text { Strongly } \\
\text { Disagree }\end{array}$ \\
\hline Positive attitude towards my workplace or business & 4.510 & .671 & 61 & 33 & 7 & 1 & 0 \\
\hline Better team player & 4.245 & .849 & 47 & 38 & 12 & 5 & 0 \\
\hline Plan, control, and manage my business much better & 4.324 & .720 & 45 & 47 & 9 & 1 & 0 \\
\hline Turnaround time is faster & 4.245 & .710 & 39 & 51 & 10 & 2 & 0 \\
\hline
\end{tabular}

Table 6 shows that the CED training resulted in the participants positively influencing their working environment through their improved ability to plan, control, and manage their businesses. In addition, most of the participants agreed that the CED courses resulted in their being better team players, together with a faster turnaround time. These results confirm research hypotheses $\left(\mathrm{H}_{2 a}\right.$ ) that the knowledge acquired through the entrepreneurship training offered by the CED contributes to the general business results of the entrepreneurs who attend the training and $\left(\mathrm{H}_{2 b}\right)$ that Entrepreneurs' work attitudes change as a result of the entrepreneurship training.

\section{Discussion}

SMEs plays an important role in emerging economies with its capacity to create employment opportunities and contribute 
to a country's GDP. However, the training of adult entrepreneurs remains a challenge as there are no integrated frameworks that exit on adult entrepreneurship training nor is there any consensus as to the components that should be included in such training initiatives. The main objective of this research was to investigate an adult entrepreneurship program in terms of its content, delivery methods and outcomes as experienced by entrepreneurs. The results are discussed in the ensuing section.

The results showed that the entrepreneurs were mostly able to apply the knowledge contents of the Bookkeeping, Production Management, Personal Development and Marketing and Sales Modules in their Businesses. The results however showed that the knowledge contents of the Communication Skills, General Business Management, Leadership and Ethics and Tendering Process Modules need slight improvement to be usable for entrepreneurs. The results are in line with Henry et al. (2005b), who pointed out that training courses should be more specific.

As regards the training methods used, the results showed that lecturing was rated as the most effective way of training. Lecturing was primarily used, supported by small discussion groups and team activities. Practical exercises and case studies were also used to transfer knowledge. Although used quite often during the execution of the training program, role playing, DVDs and mentorship were indicated to be used the least. These results, however, should be interpreted with caution. Taking into account the highest level of education of the respondents, these methods seem to be effective, as they are the only training methods known to the respondents. Team activities and practical exercises were also rated as effective. Scholars support the less traditional way of teaching and the adoption of more practical teaching, like role playing, simulation games, and problem solving exercises (Antonites, 2003; Isaac et al., 2007; Solomon, 2004).

Case studies were rated fourth lowest. A possible explanation for this is that there is a dearth of Namibian case studies, and the entrepreneurs found it difficult to relate to foreign case studies. Role play was rated third lowest. This result should also be interpreted with caution, as role play was not used in the traditional way but was applied in a "presenter-style" feedback session. Videos and DVDs received the second-lowest rating as a medium of knowledge transfer. A possible explanation for this could be a language barrier, as no local educational DVDs exist, and mainly American or Australian DVDs were used. The English spoken in these DVDs is usually on a high level, making it more difficult for a non-English-speaking entrepreneur to understand. Mentorship was rated the lowest. Finding skilled and trained mentors in the remote towns of Namibia was a challenge for the researcher. The qualities required of a good entrepreneurial mentor in small communities are recommended as an area for further research.

The results showed that most of the entrepreneurs indicated an increase in customers, improved financial systems, more formal marketing structures, an increase in turnover, a better understanding of buying procedures, and the expansion of the business as a results of the training. Having better business skills and a basic understanding of business management led to the increase in turnover and customers (Antonites, 2003; Bester and Albertyn; 2007; Botha et al., 2007; Pretorius et al., 2005; Solomon, 2004).

The results show that the training program resulted in the participants positively influencing their working environment. The results are in line with Mwasalwiba (2010) who states that entrepreneurship education should influence attitudes, values, and general community cultures. The second-most reported attitude change was in the area of planning, controlling, and managing the business to a higher degree. Due to a lack of management and planning skills in entrepreneurs this training program contributed to better planning, controlling, and management skills in the entrepreneurs.

\subsection{Implications of the research}

This research makes important theoretical, methodological and practical contributions. This research makes an important contribution to the current body of knowledge on adult entrepreneurship and, specifically, the training of these individuals. Currently, very limited research and knowledge exist on the effectiveness of adult entrepreneurship training programs on the African content, with no research currently existing in the Namibian context. The present research study creates new knowledge on the contents that should be part of an effective adult entrepreneurship training program. This knowledge can be disseminated to other program development initiatives for the training of entrepreneurs. The present study also created new knowledge in terms of the learning methods that can be applied to ensure the effective transfer of knowledge in a developing market, such as Namibia.

This research makes a methodological contribution in the sense that a questionnaire was developed to determine the effectiveness of an adult entrepreneurship program in the transfer of knowledge. The results obtained from the questionnaire were sufficient to meet the objectives of this research. Thus, the questionnaire can be used for further 
research to determine the effectiveness of other entrepreneurship training and related programs.

This research is of practical value to various stakeholders in the Namibian context. First, this research provides important information to the national government of Namibia about the current state of entrepreneurship in Namibia, and the potential contribution that an adult entrepreneurship program can make towards job creation, sustainable economic growth, and to the achievement of the objective as set out by Vision 2030. Secondly, this research makes an important practical contribution for all institutions that focus on adult entrepreneurship training. This research, inter alia, highlights the components that should be part of such training programs, as well the appropriate training methods that should be used in the transfer of knowledge for adults. This study can be used as an example of how to develop adult entrepreneurship programs that can be effectively applied to train future entrepreneurs.

\subsection{Limitations and Recommendations}

As with any research study, this study also has some limitations. The first limitation is related to the limited knowledge that currently exists on the evaluation of adult entrepreneurship programs, especially developing countries, such as Namibia. This made it difficult to interpret the results of the present study. The second limitation is related to the sampling technique. A purposive convenience sampling technique was used in this research. This means that the results of this research cannot be generalized to other populations. However, the intention of this study was not generalization of the results. The third limitation is related to the nature of the research design. A cross-sectional research design was used in this study, which means that the data were collected over a short period of time. Therefore, no cause-and-effect inferences can be made from the results. Finally, this study relied on self-reporting measures. This means that the results are based on the subjective opinions of the respondents.

For future research, it is recommended that a mixed-method research approach be followed, using a variety of data-collection techniques, such as interviews, focus groups, and document analyses, to ensure the verification and triangulation of the quantitative research results. The present study is the first of its nature to be conducted in the Namibian context. It is proposed that follow-up studies be conducted to determine whether the entrepreneurship training program is sustainable, and if it meets the requirements of entrepreneurs over the long term. This research only included the entrepreneurs who had participated in the entrepreneurship training program. For future research, it is recommended that other stakeholders, such as the national government, are also involved to gain their perceptions of entrepreneurship training. In addition, the customers/clients of the entrepreneurs can be involved to determine the quality of service they receive from the respective entrepreneurs' businesses.

\subsection{Conclusion}

To conclude, in the last couple of years, due to globalization, a scarcity of recourses, and massive layoffs by corporations, surviving on one's own has become increasingly important. As a result, entrepreneurship activities become the way of living for a considerable number of the world's population. This research highlighted the importance of equipping entrepreneurs with the necessary knowledge and business acumen not only to create employment opportunities but also make a sustainable contribution to the economy of an emerging market. It is with optimism that research of this nature motivates other countries to invest in the entrepreneurs as they are the future to economic growth and prosperity.

\section{References}

Antonites, A. J. (2003). An Action Learning Aroach to Entrepreneurial Creativity, Unpublished Doctoral Thesis, University of Pretoria, Faculty of Economic and Management Sciences.

Botha, J.M., Van der Merwe, M.E., Bester, A., \& Albertyn, R.M. (2007). Entrepreneurial skill development: Participatory action research aroach in a rural community. Journal of Family Ecology and Consumer Services, 35, 9-16.

Brown, D.B. (2011). An Experiential Aroach to Organisation Development (8 ${ }^{\text {th }}$ Ed.), Pearson Education Inc., Uer Saddle River, New Jersey.

Chua, A.Y.K. \& Goh, D.H. (2009). Why the whole is more than the sum of its parts: Examining knowledge management in acquisitions. International Journal of Information Management, 29, 78-86.

Cooper, D.R. \& Schindler, P.S. (2008). Business Research Methods, McGraw-Hill Irwin.

Cranfield, D.J. \& Taylor, J. (2008). Knowledge Management and Higher Education: A UK Case Study. The Electronic Journal of Knowledge Management, 8, 85-100.

Cresswell, J. (2009). Research Design: Quantitative, Qualitative and Mixed Methods Approaches (3rd ed.). New York: Sage. 
Delfmann, H. \& Koster, S. (2012). Knowledge transfer between SMEs and higher education institutions. Industry and Higher Education, 26, 31-42.

Dohse, D. \& Walter, S.G. (2012). Knowledge context and entrepreneurial intentions among students. Small Business Economics, 39, 877-895.

Fiet, J. (2000). The pedagogical side of entrepreneurship theory. Jounal of Business Venturing, 16, 101-117.

Henry, C., Hill, F. \& Leitch, C. (2005a). Entrepreneurship Eduation and Training: Can entrepreneurship be taught? Part 1. Education \& Training, 47, 98-111.

Henry, C. H. (2005b). Entrepreneurship Education and Training: Can Entrepreneurship be taught? Part II. Education \& Training, 47, 158-159.

Howell, K.E. \& Annansingh, F. (2013). Knowledge generation and sharing in UK Universities: A tale of two cultures. International Journal of Information Management, 33, 32-39.

Isaac, E., Visser, K., Friedrich, C. \& Brijlal, O. (2007). Entrepreneurship education and training at the Further Education and Training (FET) level in South Africa. South African Journal of Education, 27, 613-629.

Kailer, N. (2009). Entrepreneurship Education: Empirical findings and proposals for the design of entrepreneurship Educationconcepts at Universities in German speaking countries. Journal of Enterprising Culture, 17, 201-231.

Kirkley, W.W. (2010). Self-determination and Entrepreneurship: Personal values as intrinsic motivators of Entrepreneurial behaviour. Auckland, New Zealand: Massey University.

Klinger, B. \& Schündeln (2007). Can Entrepreneurial Activity be Taught? Quasi-Experimental Evidence from Central America, Harvard University: CID Working Paper No. 153.

Knockaert, M., Ucbasaran, D., Wright, M., \& Clarysse, B. (2011). The Relationship between knowledge transfer, top management team composition and performance: The Case of Computer-Based Entrepreneurial Firms. Entrepreneurship Theory and Practice, 35, 777-803.

Laal, M. (2010). Knowledge Management in Higher Education. Procedia Computer Science, 3, 544-549.

Lalani, A. (2008). Barriers to entrepreneurship and in an east African context: A case study of Kenya and Tanzania. Nottingham: Nottingham University Business School.

Mwasalwiba, E.S. (2010). Entrepreneurship Education: A review of its objetives, teaching methods, and impact indicators. Education and Training, 52, $20-47$.

Pretorius, M., Nieman, G., \& Van Vuuren, J. (2005). Critical evaluation of two models for entrepreneurship education: An improved model through integration. International Journal of Educational Management, 19, 413 - 427

Rae, D. (2006). Connecting enterprise and graduate employability: challenges connecting enterprise and graduate employability: challenges to higher education culture and curriculum? Education \& Training, 49, 605-619.

Rahimi, H., Arbabisarjou, A., Allameh, A.M. \& Aghababaei, R. (2011). Relationship between Knowledge Management Process and Creativity among Faculty Members in the University. Interdisciplinary Journal of Information, Knowledge and Management, 6, 1733.

Rukoro, A.V. (2012). Namibia's Initiative to Combat Corruption and to Promote Ehtihcal Behaviour, 8th International Anti-corruption conference, Windhoek: Anti Corruption Commission Namibia.

Solomon, G. (2004). Entrepreneurship and the impact of entrepreneurial orientation training on SMMEs in the South African context: $A$ Longitudinal Aroach. Unpublished Doctoral Thesis, University of Pretoria.

SPSS Inc. (2012). SPSS 20.0 for Windows, Chicago, IL: Author.

Unger, J.M., Rauch, A., Frese, M. \& Rosenbach, N. (2011). Human capital and entrepreneurial success: A Meta-analytical review. Journal of Business Venturing, 26, 341-358.

Van Aardt, I. H., Hewitt, M., van der Bank, J., Bezuidenhout, S., and Visser, T. et al. (2011). Entrepreneurship and New Venture Management, New York: Oxford University Press Southern Africa (Pty) Ltd. 